\title{
Optimal Placement of Capacitor Bank in Reorganized Distribution Networks Using Genetic Algorithm
}

\author{
Emma Bakker \\ Department of MBA or \\ business management/ Leiden \\ University, Netherlands
}

\author{
Vahid Deljou \\ Department of electrical \\ Engineering/ Islamic Azad \\ University, West Tehran \\ Branch, Iran
}

\author{
Javad Rahmani \\ Department of digital \\ electronics Engineering/ \\ Islamic Azad University, \\ Science and Research Branch,
}

\begin{abstract}
Capacitor optimal placement is one of the most important designs and control issues of power systems in order to reduce network losses, improve the voltage profile, reduce the reactive load, and reducing the power factor. The distribution network operator, taking into account two major goals of reducing real power losses and maximizing the return on investment required for installation of capacitive banks for sale to the transmission system, obtains the position, number, and capacity of capacitive banks. In this paper, the optimization problem is formulated for different values of the parameter "reactive energy value". After evaluating the objective function and implementing an optimization algorithm for each value of this parameter, the arrangement and capacitance of the capacitors in the network load nodes are obtained. Meanwhile, using the objective function defined in this paper, you can obtain the threshold for the sale of reactive energy, and by selling it to the transmission network, the investment in installing capacitor banks will be profitable for the distribution network operator.

Keywords: Capacitor, Optimal Placement, Genetic Algorithm, Wind Energy Conversion Systems Reactive Power, Power Factor.
\end{abstract}

\section{INTRODUCTION}

Generally, in alternating current networks, the apparent power received from the generators is divided into two parts: real power (active) and reactive power. The way this division depends on the power factor of the consumers, that is, the more power factor closer to 1 , the greater is the true power share and the less is imaginary power contribution. Due to the fact that many consumers in which the coil or inductor play a significant role, they are the resistive-inductive consumers, and because of the energy saving feature in the inductors, there is always an amount of power that moves between the network and inductor which cannot be used and is wasted on the path through the wires and cables $[1,2]$. As a result, generators need to produce more power and increase the current flow, which, with the increasing of the current flow, the capacity of the transmission lines reduces for real power transmission. In fact, all the reactive power required for loads, lines, and transformers should be produced at the transmission level. Also, the power loss in the distribution networks is in the form of heat, voltage drop, and reduction in efficiency. The reactive power compensation means that the reactive power needed is generated besides the load instead of supplying through the generators of the power plant $[3,4]$. This distribution can be done at the distribution and overdistribution level by parallel capacitors. Basically, the more capacitors are installed near the consumer centers, the higher the efficiency of the network will be. The use of parallel capacitors makes it possible to utilize the capacity of the transmission lines for more active power transmission [5, 6]. The power consumed by electricity subscribers varies, as a result of their power factor characteristics. By producing reactive power by capacitors, the effects of the reactive components reduce and the power factor increases, which will result in more favorable technical conditions for energy transfer [7-12].

In 1956, the first steps were taken to optimize the placement of capacitors in distribution networks, and this has continued so far. From the presented methods, there are many methods such as mathematical and analytic methods including two noncompressed methods (Kant Tuck theory, Hysin method, reduced gradient method, and quadratic programming) and compact (linear programming and nonlinear programming) [13-18]. [19-22] proposed a nonlinear programming model to find optimal locations of facilities throughout the network. In the past and the use of the birds breeding algorithm in 2007.

This paper presents a solution based on the genetic algorithm for optimal placement of capacitors.

\section{GENETIC ALGORITHM}

Genetic algorithms use Darwin's natural selection principles to find the optimal formula for predicting or matching patterns. According to Darwin's survival evolution theory, living organisms in the next generation are better than the previous generations [23, 24]. In general, these algorithms consist of four parts of the fitting, display, selection and modification function. It is briefly said that the genetic algorithm is a programming technique that uses genetic evolution as a problem-solving model. This is an evolutionary search algorithm to find an approximated optimal solution starting with a set of the initial solution [25-28].

The input of this program is a problem that needs to be solved and solutions are coded according to a template. Fit fitness evaluates candidate responses. First, a select number of inputs, $\mathrm{x} 1, \mathrm{x} 2, \ldots . . \mathrm{xn}$, which belong to the $\mathrm{X}$ space, are selected and represent them as a vector $\mathrm{X}=(\mathrm{x} 1, \mathrm{x} 2, \ldots, \mathrm{xn})$. This input vector is called the organism or the chromosome and the group of chromosomes is called colonies or populations [29, 30]. In each period, the colony grows and evolves in accordance with certain laws that indicate biological evolution. For each chromosome xi, there is a fitness function $\mathrm{f}(\mathrm{xi})$. Stronger elements or chromosomes that are closer to their current value, they are more likely to survive in other periods and re-produce, and the weaker ones will die. In other words, this algorithm keeps the inputs that are closer to the optimal answer and ignores the rest. Another important step in the algorithm is the birth or production of a child that occurs once in each period. Children can be generated through crossover and mutation operators at each 
step [31-34]. The contents of the two chromosomes that occur in the production combine to create a new chromosome called a child. Some of the genes are transmitted from the father and some others from mother to child, where the genes mutate from father to mother or vice versa, are called compound combinations 4. In addition, during a period, a series of chromosomes may find a gene mutation. A gene that does not exist in the parent is created in the child. As stated above, each entry $\mathrm{X}$ is located on a vector number $\mathrm{X}=(\mathrm{x} 1, \mathrm{x} 2, \ldots, \mathrm{xn})$. For the implementation of the genetic algorithm, each entry must convert to one chromosome. In the zero step, a bunch of inputs $X$ is randomly selected. Then, for each period, the fit value is calculated and the operators of production will change and select. When the fit value is obtained or the chromosomal matched around the constant value oscillates, because of the gene mutation operator the total matching of the chromosomes does not remain constant at all, the algorithm ends.

\section{OPTIMAL REACTIVE POWER COMPENSATION IN A REDISTRIBUTED DISTRIBUTION GRID}

\subsection{Expression of Optimal Capacitor Positioning Approach with Attitude to Restructuring in Electricity Industry}

Considering the compensation system, the compensation in the medium pressure distribution network and the MV / HV buses in the middle of the transmission and distribution, there is virtualization in a reactive power generator and there is no need to carry this power from the transmission system to the distribution system [35]. With the production of reactive power in HV buses, the demand for a distribution system or more can be provided. In fact, there is the advantage that there is no need for reactive power transmission and installation of energy systems. In this new scenario, investing in the installation of the compensation system for the distribution system operator has two advantages of reducing the loss of power and increasing the profit from the sale of reactive power to the network operator. The amount of economic allocation for the distribution system operator cannot be lower than a certain threshold value $[36,37]$.

In fact, if the system obtain the reactive power transfer at a cost above the threshold cost, it will be economically feasible to install capacitor banks and exploit them for the distribution network operator, and if this cost be lower than the threshold, according to the distribution system operator, there is no need to install a compensating system, more than what is needed to reduce the distribution network losses, while the production and transmission of reactive power is cheaper than buying it from Distribution Network [38-40]. The optimization model presented in this paper is examined from the point of view of the distribution network.

In a detailed description of the procedure, the program will be run and the system losses will be achieved before the compensation. Then, a target function and a suggested price for the sale of one kilo VAR of reactive energy to the transmission network are defined. In fact, the new target function, in relation to the target functions used in the previous methods, has an additional sentence that relates to the revenue from the sale of reactive power to the transmission network. By defining the objective function and using an optimization algorithm (genetic algorithm), the search begins to find the optimal response. By finding the optimal answer for a suggested price, the price is increased by one step, and again the load and the genetic algorithm is performed to find the optimal capacitor arrangement for the new price, and finally, the network losses are calculated after compensation. This process continues to the point where the increase in the price of reactive energy sales to the transmission network will not increase casualties compared to pre-compensation network losses. In fact, reducing the losses is more important than increasing the economic benefits.

\subsection{Formulation of the Problem}

In order to optimize the target function, the two current positions (Before compensation) and a new position (design response) are compared. The economic components of the current situation are as below:

- Variable cost related to power losses in distribution network lines

- Variable cost related to power losses in the transformer $\mathrm{MV} / \mathrm{HV}$

After exploiting the system in a new position and inserting capacitive banks in the MV / HV distribution network nodes, the economic components of the new position are:

- The variable cost is related to the new amount of line losses that is definitely less than the losses in the previous state.

- Variable cost related to the new value of MV / HV Transformer losses

- Revenues from sales of reactive power to the transmission system

- The total cost of installation of capacitive banks: All of these components are reviewed over a year. For this time period, load variations and capacitor banks are considered.

The condition (1) or the power loss per hour h, taking into account the daily load and changing the clock to the hourly load of each node of the medium network, is expressed as follow:

$P_{\text {loss }}(\mathrm{h})=\sum_{i=1}^{n_{r}} \frac{R_{i}}{V_{i}^{2}}\left[\left(P_{i}(\mathrm{~h})\right)^{2}+\left(Q_{i}(\mathrm{~h})-Q_{c i}(\mathrm{~h})\right)\right]^{2}$

In which, $\mathrm{Q}_{\mathrm{ci}}$ is the capacity of capacitor banksat node $\mathrm{i}, \mathrm{P}_{\mathrm{i}}(\mathrm{h})$ and $\mathrm{Q}_{\mathrm{i}}(\mathrm{h})$ are real and reactive powers of the ith branch (including the loads and losses under the $\mathrm{i}$-th branch) and $\mathrm{n}_{\mathrm{r}}$ is the total number of branches of the network.

In this case, because the current position is checked, no capacitance is installed, $\left.\mathrm{Q}_{\mathrm{ei}}(\mathrm{h})=0\right)$. Energy losses in a year are as follows:

$E_{\text {loss }}=365 \sum_{h=1,24} P_{\text {loss }}(\mathrm{h})$

The condition (3) is equivalent to the condition (1), in which $(h)=0$ ). Condition (2) represents the losses in the MV / HV transformer station at hour $\mathrm{h}$.

$P_{\text {lossTR }}(\mathrm{h})=\frac{R_{T R}}{V^{2}}\left[\left[P(h)^{2}\right]+\left[\mathrm{Q}(\mathrm{h})-Q_{c}(\mathrm{~h})\right]^{2}\right]$ 
The $\mathrm{R}_{\mathrm{TR}}$ is the transformer series resistor, $\mathrm{V}$ is the rated voltage of the intermediate voltage, and $\mathrm{P}(\mathrm{h})$ and $\mathrm{Q}(\mathrm{h})$ represent the active and reactive power requirements of the network (including loads and losses) that are in the medium voltage transformer. In the formula above, the expression $\mathrm{Q}_{\mathrm{c}}(\mathrm{h})$ is zero and $\mathrm{P}_{\text {lossTR }}$ represents the loss of the transformer prior to the compensation. The loss of distribution transformers has been neglected due to the insignificance of their series resistance.

The energy losses per year for the transformer is as follows:

$E_{T R}=365 \sum_{h=1,24} P_{\text {lossTR }}(\mathrm{h})$

The condition (4) is equivalent to the condition (2), which is opposite zero. In fact, this condition indicates the actual operating conditions of the capacitor banks connected to the $\mathrm{MV} / \mathrm{HV}$ modulus of the transformer at any time of the day.

The economic benefits resulting from the loss of network losses is as follow:

$R_{E T}=\left(C_{E T b}-C_{E T a}\right)=\left(E_{\text {lossb }}-E_{\text {lossa }}\right) C_{E T}$

Which $C_{E T b}$ and $C_{E T a}$ represents the costs of energy losses before and after compensation, and $E_{\text {lossb }}$ and $E_{\text {lossa }}$ are the energy losses before and after compensation, and $C_{E T}$ indicates the unit cost of energy in terms of (KWh / Rials), which according to the budget law of year 87 is equal to 773 Rials.

The resulting losses in MV / HV transformers are calculated as follows:

$$
R_{E T R}=\left(C_{E T R b}-C_{E T R a}\right)=\left(E_{T R b^{-}} E_{T R a}\right) C_{E T}
$$

$C_{E T R b}$ and $C_{E T R a}$ are the costs of the transformer losses before and after the compensation, and $E_{T R b}$ and $E_{T R a}$ are the energy losses before and after the compensation.

If the phrases $R_{E T R}$ and $R_{E T}$ are lowered to zero, this means that for the distribution network operator not only economic gain is not achieved, but also incurred economic losses, while the cost of installation of capacitive banks is higher compared to the cost of reducing the losses.

In order to express the condition (5), that is, the proceeds from the sale of reactive power to the transmission system, the Rial value of the reactive production service unit (one kilo VAR hour) $\mathrm{R}$, and the total value of the Rial of the reactive power of the capacitor banks assigned to the distribution network $R_{T}$. In this case, we will have:

$$
\begin{aligned}
& R_{\mathrm{T}} \\
= & 365 \mathrm{R} \sum_{i=1}^{n} \sum_{h=1}^{24} Q_{c i}(h)
\end{aligned}
$$

Where $\mathrm{n}$ I s the total number of network chains and

$$
Q_{c i}(h) \text { is the capacitance bank at } \mathrm{h} \text { is in chin i. }
$$

The main problem is determining the optimal response obtained from the genetic algorithm for different values of the parameter $\mathrm{R}$.
Unit R (kvarh / Rials) is the economic value of reactive energy.

Finally, the condition (6) is equivalent to the total cost of the purchase, installation, and maintenance of capacitor banks, which is obtained by multiplying the cost of one kilo VAR capacitive bank $\left(\mathrm{C}_{\text {inst }}\right)$ in the capacity of the entire installed capacitor banks $\left(\mathrm{Q}_{\text {cinst }}\right)$.

$$
\mathrm{C}_{\text {instT }}=\mathrm{C}_{\text {inst }} \times \mathrm{Q}_{\text {cinst }}
$$

In general, an indicator should be defined to assess the answer to the problem, the index in this paper is called the return on capital. This indicator represents the difference in revenue and expenses over a year in the distribution network.

\subsection{Solve the problem of capacitance in a redistributed distribution network with a genetic method}

The steps to solve the problem are as follows:

First, enter the network information and power flow is done, then all the network load buses are considered as the candidate for the capacitor installation location. Initial capacity is then determined for the specified sites to begin the search using the genetic algorithm and the objective function. Input data of this program, active and reactive load data of the network, impedance and admittance lines, the maximum number of capacitors per bus, the rial equivalent of one kilowatt hour of energy, the purchase and installation cost per kilo VAR capacitor and the cost of sales one kilo of hours of reactive energy to the transmission network. The decision variables in this issue are the position and size of the nominal capacitive banks and their control variables, including the maximum capacitance banks size, the allowed range of buses' voltage and the maximum allowable amount of reactive energy sold to the transmission network, in such a way that the generator does not get unstable. The output data of this program are the capacitance and final position of the capacitors in the network, the active and reactive losses of the grid after compensation, the MV / HV transformer losses, and the amount of energy sold to the transmission network. Objective Function.

$$
\frac{R_{E t}+R_{E T R}+R_{T}-C_{\text {inst } T}}{C_{\text {inst } T}}
$$

Maximize $=$ max objective function

The constraints of the objective function are:

$$
\begin{aligned}
& V_{i \min }<V_{i}<V_{i \max }, Q_{c(\min )} \leq Q_{c} \leq Q_{c(\max )} \\
& 0 \leq n_{i} \leq n_{i(\max )}
\end{aligned}
$$

Which $\mathrm{V}_{\mathrm{i}}$ represents the value of the voltage in the bus-bar $\mathrm{i}$, $\mathrm{n}_{\mathrm{i}}$ is the number of capacitor banks in the bus-bar $\mathrm{i}$ and $\mathrm{Q}_{\mathrm{c}}$ is the value of the reactive power that can be injected to or received from the transmission network. The cost of each economic component 1 to 6 is assessed in one year. If the 
deduction is greater than zero, the income will increase as the nominal capacity increases. The price threshold is the amount for which the return on investment index changes from negative or zero to a positive amount. In order to obtain the final configuration and capacitance of the capacitors in the network for each value of $\mathrm{R}$, the program must be implemented so far as to allow the maximum number of repetitions to be allowed, or the sum of fitting the chromosomes in a generation to a constant value. Of course, in general, due to the presence of a gene mutation operator, a constant amount is not obtained, and the total fit of the chromosomes fluctuates around a constant value. In this case, the response is saturated and the optimal response is obtained from the genetic algorithm. Then $\mathrm{R}$ is increased one step and the algorithm is executed again.

The makeup and capacity resulting from the implementation of the algorithm for each value of $\mathrm{R}$ results in the highest revenue for that value for the distribution system operator. Considering $\mathrm{R}=0$, the term for selling revenues from the sale of power to the transmission network is eliminated. In this case, the goal is to find the makeup and optimal capacitance of the capacitors, regardless of the energy sales to the transmission network - and without considering restructuring in the electricity industry.

\subsection{Solution Algorithm}

According to the above, the problem-solving procedure can be summarized as follows (figure 1):

- Initial population formation (initial values of capacitance capacities in candidate positions for each chromosome from the initial population)

- Evaluation of superior values for each chromosome and evaluation of the objective function using:

$>$ Performing load flow based on the initial population of capacitors per chromosome

$>$ Calculate the losses of lines and transformers for this arrangement

$>$ Calculate the cost of installing capacitors for this arrangement

$>$ Calculation of $\mathrm{R}_{\mathrm{T}}$ for different prices of $\mathrm{R}$

$>$ Calculate the fit of each chromosome (the value of the objective function)

$>$ Determine the highest values of each population for reproduction

- Perform reproduction using combinator operators and gene mutations

- Repeat steps 2 and 3 to achieve the maximum reproduction specified or saturation of the fit function

Determine the capacitive capacity for each candidate position according to the best chromosome produced.

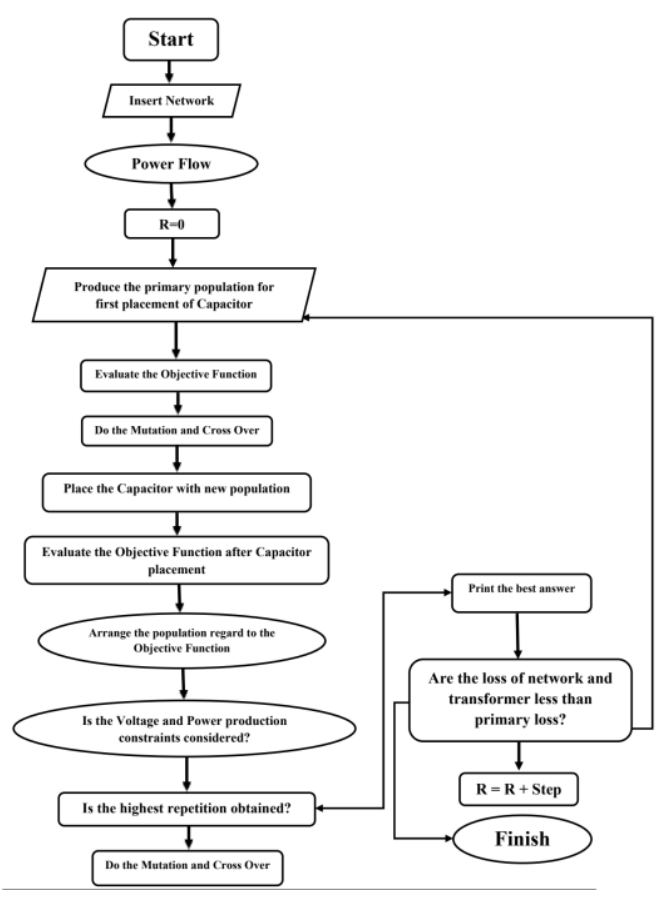

Figure 1. The algorithm for solving the problem of capacitance in a distributed distribution network with a genetic method

\section{SIMULATION AND RESULT}

The simulation of this method is performed on an IEEE radial-circular grid. A computer program in the MATLAB software environment is written based on the Genetic Algorithm and Newton-Raphson load distribution for different loading modes in the distribution network and simulation is performed with this program.

4.1 Formulation of the problem in MATLAB software space: The modeling of the test network is done using two input data matrices and line data.

\subsection{The input of each bus}

Column 1: bus-bar number

Column 2: Bus-bar Code (Bus-bar PQ: 0, Bus-bar Reference: 1, Bus-bar PV: 2)

Column 3: Voltage value in P.U

Column 4: Phase angle in degrees

Column 5: Bus load in MW

Column 6: Bus load according to MVAR

Column 7 to 10: Production Megawatts, Mega Var Production, Minimum Mega Var Production Permitted

Column 11: Reactive Power (MVAR) injected by parallel capacitors 


\subsection{Data of transmission line}

In this case, each line is marked with two nodes, with columns 1 and 2 including the number of nodes at the beginning and end of the line. In column 3 to 5 resistance, the reactance and half the total Susceptance of the line are expressed in terms of P.U based on the MVA. Due to the insignificance of the capacitance susceptibility of the line in distribution networks, its value is neglected. The last column of this matrix is used to adjust the transformer tap. For lines, number 1 should be entered in this column. The line information can be entered in any order, but if the input values are for the transformer, the side with the tap is considered as the left bus-bar. Once the network and line information is entered, there must be a connection between the load distribution program and the genetic algorithm. The output of the genetic program should be referred to as the input of column 11 of the data file. For this purpose, we have to consider the network load nodes as the initial population of the genetic algorithm and allocate a suitable initial capacity as inputs to them. Because of the discrete capacities of existing capacitor banks, chromosome bits are valued at the same level as the actual stacks of capacitor banks. In this program, the return on investment indicator is used to determine the fitness of the objective function.

\subsection{Simulation on Roy-Billinton Test System (RBTS): Run the program assuming a variable daily load within a year}

The proposed method on the Roy - Billinton (shown in Figure 2 of the single-mode model diagram of the sample network) with the assumption of changing the load over a 24-hour period of a day, is reviewed and the resulting responses are examined.

In the Billinton test network, bus 4 of the system has 71 chunks and 38 nodes. The capacitive capacities of the capacitor banks in the load cells of this network are 150 kilo Var. The maximum number of capacitor banks nominated at a node is 8 (maximum 1200 kilo Var) and the maximum number of $1,200 \mathrm{kV}$ capacitive banks to be installed at the station is $230 \mathrm{kV}(28 \mathrm{kV}$ ) (up to 33.6 megawatts) The 33 / $230 \mathrm{kV}$ transformer has a capacity of $160 \mathrm{MVs}$ and a series resistance of $0 / 024 \mathrm{ohm}$. The losses before the capacitor are installed is $739 \mathrm{~kW}$. The average active and reactive loads connected to this network are respectively $24.578 \mathrm{MW}$ and 15.232 MVAR, respectively.

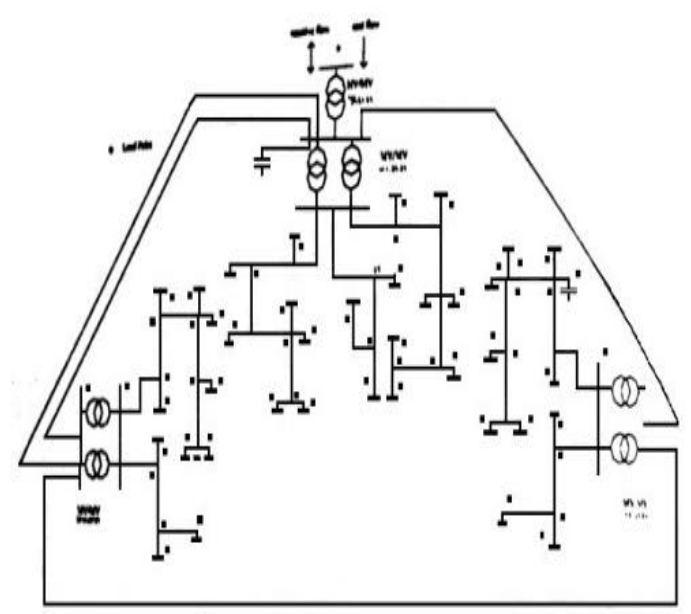

Figure 2. Single-line diagram of Bus-bar 4 in Roy - Billinton test system

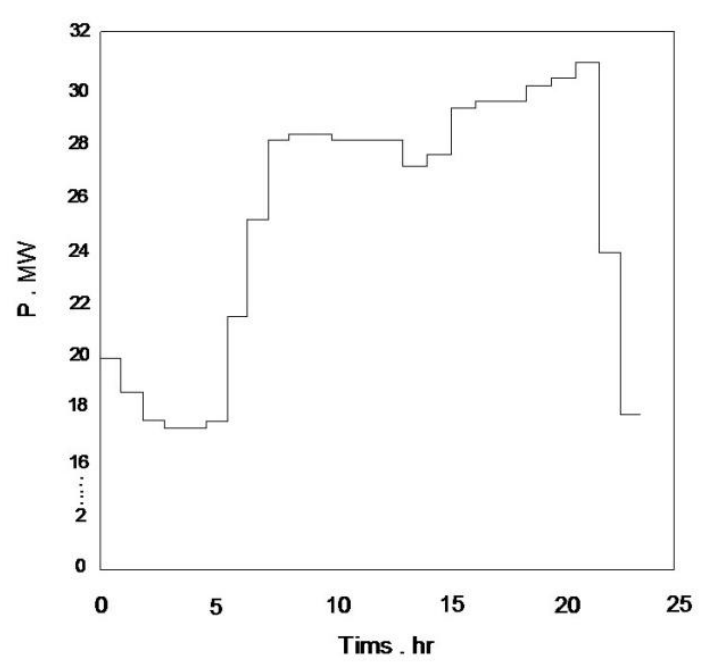

Figure 3. 24-hour load diagram of Bus-bar 4 in Roy Billinton test system

By executing a program for a sample network with a 24-hour load diagram, for each value of $\mathrm{R}$ (the equivalent of a Rial per kilo Var per hour), and implementing the genetic algorithm at multiple times, the final energy dissipation in the network, the energy lost in the transformer 33/230 Within one year, the total capacitive capacity and capital return indicator are in accordance with Table (1).

It is seen that in this case, for the values of $\mathrm{R}$ near zero, the term capacitance of the nominal capacitor is often constant and the fit of the objective function is negative. As $R$ increases, the return on capital increases gradually, meanwhile capacitive capacitance increases. This increase is slowing down to reach the threshold price, and after reaching the threshold price and positive fit, the objective function increases with a higher rate. This process is consistent with what was previously expected, installing a surplus capacitive bank on the distribution network needs a cost-effective economy if the operator purchases a reactive energy transfer 
network at a reasonable price from the distribution network. In this case, with a daily change in load, the threshold value of $\mathrm{R}$ is about 55 Rials. In fact, for the sale of one kilo Var of reactive energy per hour, the reactive power of 55 Rials and more to the transmission network operator, the investment in the installation of capacitor banks is more profitable for the distribution network operator than reducing the losses of the distribution network. The power loss diagrams in the grid lines and main station transformer, the installed capacitance and the return indicator of capital (Figures 4 to 7) for the different values of the parameter $\mathrm{R}$ represent this fact.

Table 1. Results from program execution for change 24hour load parameter

\begin{tabular}{|c|c|c|c|c|}
\hline $\begin{array}{c}\text { (Rial/Kvarh) } \\
\text { R }\end{array}$ & $\begin{array}{c}\mathrm{P}_{\text {loss }} \\
(\mathrm{MWH})\end{array}$ & $\begin{array}{l}P_{\text {loss TR }} \\
(\mathrm{MWH})\end{array}$ & $\begin{array}{l}\mathrm{Q}_{\text {sinst }} \\
\text { (kvar) }\end{array}$ & ROI \\
\hline 0 & $2926 / 38$ & $99 / 39$ & 13800 & $-0 / 89735$ \\
\hline 5 & $2936 / 73$ & $99 / 45$ & 14550 & $-0 / 80974$ \\
\hline 15 & $2972 / 54$ & $99 / 50$ & 14550 & $-0 / 63655$ \\
\hline 25 & $2869 / 35$ & $99 / 52$ & 18900 & $-0 / 46279$ \\
\hline 35 & $3247 / 47$ & $100 / 36$ & 21150 & $-0 / 32181$ \\
\hline 45 & $3241 / 71$ & $100 / 65$ & 21150 & $-0 / 14872$ \\
\hline 55 & $3557 / 13$ & $100 / 93$ & 24900 & $0 / 00299$ \\
\hline 60 & $3728 / 24$ & $100 / 99$ & 27000 & $0 / 055728$ \\
\hline 65 & $3769 / 54$ & $101 / 23$ & 27600 & $0 / 16087$ \\
\hline 70 & $3993 / 10$ & $101 / 44$ & 27750 & $0 / 2555$ \\
\hline 75 & $4006 / 69$ & $102 / 76$ & 30900 & $0 / 32981$ \\
\hline 80 & $4232 / 14$ & $104 / 95$ & 31650 & $0 / 44149$ \\
\hline
\end{tabular}

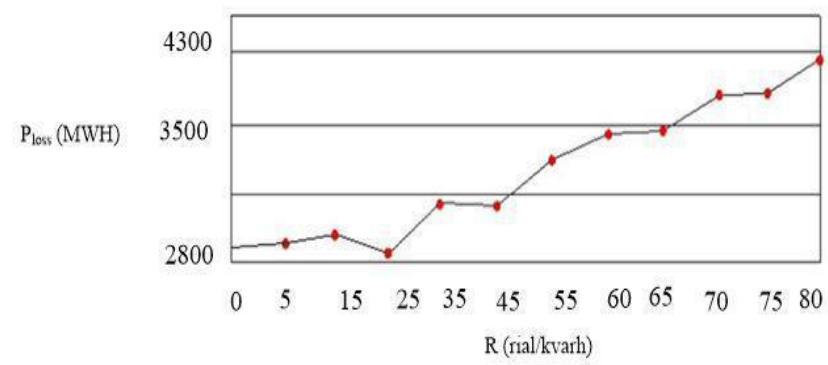

Figure 4. Energy lost in network grid for different values of the parameter $\mathrm{R}$ during a year

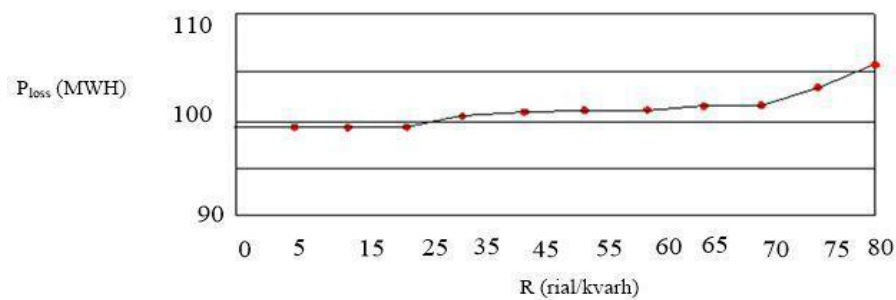

Figure 5. The lost energy diagram in the transformer 33/230 for different values of the parameter $\mathrm{R}$ during one year

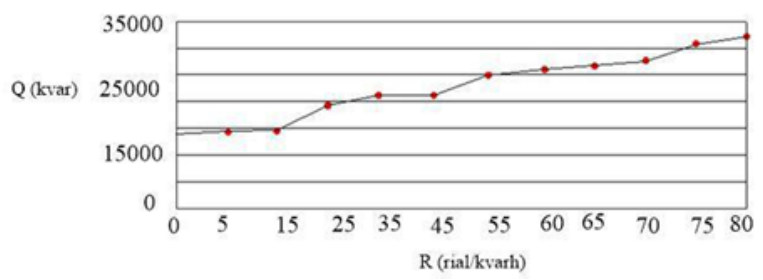

Figure 6. Capacitive capacitance diagram on the network for various values of $R$

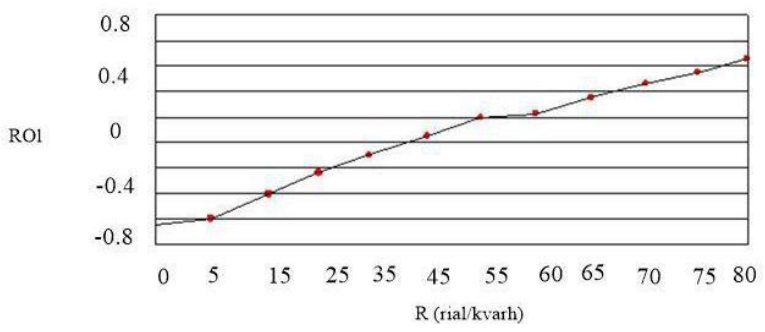

Figure 7. Return indicator of capital for various values of R

Also, in this program, the capacity of the capacitor bank is determined at load nodes at any time of the day. In fact, on the capacities obtained, it is easy to determine the switching state of the clock per hour of the capacitors.

In Figure 8, the switching state is provided in the state $\mathrm{R}=0$. Similarly, the switching status at other prices is also indicated in this program, due to the high volume of information, the total annual energy exchanged in $\mathrm{R}$ is presented. In Figure 9, reactive energy exchanged during one year for each parameter of $\mathrm{R}$ is presented.

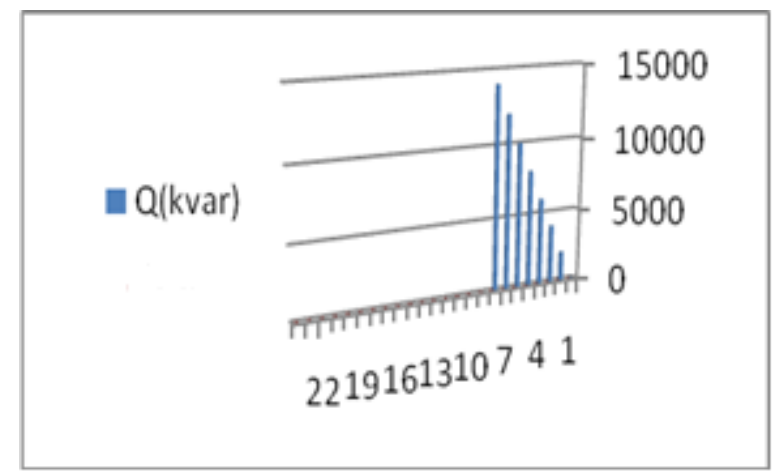

Figure 8. Change the nominal capacitance in length Overnight for $\mathrm{R}=0$ 


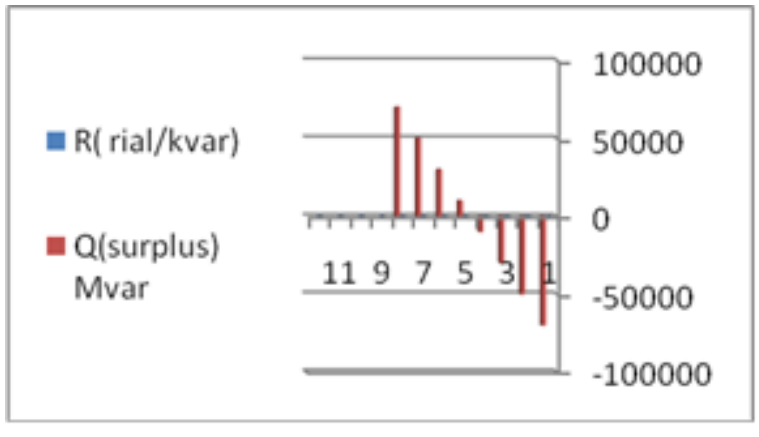

Figure 9. Reactive energy purchased from / sold to transmission network over a year

\section{CONCLUSION}

By formulating the problem of determining the position and capacitance of the capacitors in a redistributed distribution network and examining the results obtained from the implementation of the above method for the Roy - Billinton test network, the results are:

- Prior to the restructuring, a distribution network is required to continuously improve the voltage profile and reduce network losses, and this is possible through the installation of a reactive power compensation system in the distribution network.

- In the redistributed distribution networks, the capacity of the capacitor to reduce network losses depends on market conditions.

- In this new scenario, investing in the installation of a compensation system for the distribution system operator has two advantages in reducing the loss of power and increasing the profit from the sale of reactive power to the transmission network operator.

- The economic value assigned to the reactive power sold to the transmission system (R) should be reasonable. This economic value for a distribution system operator cannot be reduced to a certain threshold value.

- If the system gets the reactive power at a cost higher than the threshold cost, it is economically feasible to install capacitor banks and exploit them for the distribution network operator, and if this cost For the transmission system be less than threshold value, according to the distribution system operator, there is no need to install a compensation system - more than what is needed to reduce the distribution network losses - and this occurs when the generation and transmission of reactive power It's cheaper than buying it from the distribution network.

- For $\mathrm{R}$ values less than the threshold value, the nominal capacity of the capacitor and, consequently, the network losses are relatively constant, and changes in this parameter lead to similar arrangements of capacitor banks in the network bushings. In this case, the reactive power generated in the distribution network is equal to or less than the reactive power level of the reactors and losses, and considering the unit price of the reactive service and the cost of the purchase, installation and maintenance of the capacitor banks may be partially or entirely get the reactive energy you need from the transmission network.

- With reaching $\mathrm{R}$ to the threshold value and increase of this parameter, the phrase "installed nominal capacitance" increases along with the return on capital.

- At the same time, with the increase in the economic benefits of investing in the installation of capacitor banks more than the amount of network required, the network losses and transformers also increase to some extent. The reason for this is that the increase in reactive power in the network load cells is more than that which increases the losses.

- If the price of reactive energy is achieved regardless of constraint, it is possible that the resulting economic benefits will not only reduce the loss of the network but also increase it. Therefore, the price increase of the threshold value is also limited.

- Most of the reactive power sold to the transmission system - due to the limitations of the number of authorized capacitor banks in the network load nodes, the maximum Megavar injected to the transmission network and the voltage limit of each shaft - is due to the nominal capacity at the MV / HV station. Therefore, it can be said that the capacitors installed in the medium pressure network shins are used to reduce the losses of the distribution network and the capacity of the MV / HV capacitor banks is related to the investment and sale of energy to the transmission network operator.

The reason that the maximum number of capacitors in the MV / HV station is higher than the network load nodes is that the MV / HV station is closer to the transmission network and a lot of bus-bars are connected to the reactive load. Therefore, it is possible to move and sell energy in this bus-bar.

\section{REFERENCES}

[1] V. Miranda, J. Ranito, and L. M. Proenca, "Genetic algorithms in optimal multistage distribution network planning," IEEE Transactions on Power Systems, vol. 9, pp. 1927-1933, 1994.

[2] F. Rahmani, F. Razaghian, and A. Kashaninia, "Novel Approach to Design of a Class-EJ Power Amplifier Using High Power Technology," World Academy of Science, Engineering and Technology, International Journal of Electrical, Computer, Energetic, Electronic and Communication Engineering, vol. 9, pp. 541-546, 2015.

[3] M. T. Andani, H. Pourgharibshahi, Z. Ramezani, and H. Zargarzadeh, "Controller design for voltage-source converter using LQG/LTR," in Texas Power and Energy Conference (TPEC), 2018 IEEE, 2018, pp. 16.

[4] M. Ketabdar, "Numerical and Empirical Studies on the Hydraulic Conditions of 90 degree converged Bend with Intake," International Journal of Science and Engineering Applications, vol. 5, pp. 441-444, 2016.

[5] M. T. Andani and Z. Ramezani, "Robust Control of a Spherical Mobile Robot," 2017.

[6] H. Pourgharibshahi, M. Abdolzadeh, and R. Fadaeinedjad, "Verification of computational optimum 
tilt angles of a photovoltaic module using an experimental photovoltaic system," Environmental Progress \& Sustainable Energy, vol. 34, pp. 1156$1165,2015$.

[7] M. Delfanti, G. P. Granelli, P. Marannino, and M. Montagna, "Optimal capacitor placement using deterministic and genetic algorithms," in Proceedings of the 21st International Conference on Power Industry Computer Applications. Connecting Utilities. PICA 99. To the Millennium and Beyond (Cat. No. 99CH36351), 1999, pp. 331-336.

[8] R. A. Gallego, A. J. Monticelli, and R. Romero, "Optimal capacitor placement in radial distribution networks," IEEE Transactions on Power Systems, vol. 16, pp. 630-637, 2001.

[9] K. Yousefpour, "Placement of dispersed generation with the purpose of losses reduction and voltage profile improvement in distribution networks using particle swarm optimization algorithm," Journal of World's Electrical Engineering and Technology, vol. 3, pp. 118-122, 2014.

[10] M. Rostaghi-Chalaki, A. Shayegani-Akmal, and H. Mohseni, "Harmonic analysis of leakage current of silicon rubber insulators in clean-fog and salt-fog," in 18th International Symposium on High Voltage Engineering, 2013, pp. 1684-1688.

[11] M. H. Imani, M. Y. Talouki, P. Niknejad, and K. Yousefpour, "Running direct load control demand response program in microgrid by considering optimal position of storage unit," in 2018 IEEE Texas Power and Energy Conference (TPEC), 2018, pp. 1-6.

[12] M. Rostaghi-Chalaki, A. Shayegani-Akmal, and H. Mohseni, "A study on the relation between leakage current and specific creepage distance," in 18th International Symposium on High Voltage Engineering (ISH 2013), 2013, pp. 1629-1623.

[13] J. Carlisle, A. El-Keib, D. Boyd, and K. Nolan, "A review of capacitor placement techniques on distribution feeders," in Proceedings The TwentyNinth Southeastern Symposium on System Theory, 1997, pp. 359-365.

[14] A. F. Bastani and D. Damircheli, "An adaptive algorithm for solving stochastic multi-point boundary value problems," Numerical Algorithms, vol. 74, pp. 1119-1143, 2017.

[15] P. M. Hogan, J. D. Rettkowski, and J. Bala, "Optimal capacitor placement using branch and bound," in Proceedings of the 37th Annual North American Power Symposium, 2005., 2005, pp. 84-89.

[16] B. Rahimikelarijani, M. Saidi-Mehrabad, and F. Barzinpour, "A mathematical model for multiple-load AGVs in Tandem layout," Journal of Optimization in Industrial Engineering, 2018.

[17] M. AlHajri, M. AlRashidi, and M. El-Hawary, "A novel discrete particle swarm optimization algorithm for optimal capacitor placement and sizing," in 2007 Canadian Conference on Electrical and Computer Engineering, 2007, pp. 1286-1289.

[18] R. Eini, "Flexible Beam Robust Loop Shaping Controller Design Using Particle Swarm Optimization," Journal of Advances in Computer Research, vol. 5, pp. 55-67, 2014.

[19] A. F. Bastani, Z. Ahmadi, and D. Damircheli, "A radial basis collocation method for pricing American options under regime-switching jump-diffusion models," Applied Numerical Mathematics, vol. 65, pp. 79-90, 2013.
[20] R. Bayindir, S. Sagiroglu, and I. Colak, "An intelligent power factor corrector for power system using artificial neural networks," Electric Power Systems Research, vol. 79, pp. 152-160, 2009.

[21] F. Rahmani, "Electric Vehicle Charger based on DC/DC Converter Topology," International Journal of Engineering Science, vol. 18879, 2018.

[22] M. Alizadeh, I. Mahdavi, S. Shiripour, and H. Asadi, "A nonlinear model for a capacitated locationallocation problem with Bernoulli demand using subsources," Int J Eng, vol. 26, pp. 1007-1016, 2013.

[23] M. Ketabdar, A. K. Moghaddam, S. A. Ahmadian, P. Hoseini, and M. Pishdadakhgari, "Experimental Survey of Energy Dissipation in Nappe Flow Regime in Stepped Spillway Equipped with Inclined Steps and Sill," International Journal of Research and Engineering, vol. 4, pp. 161-165, 2017.

[24] J. Rahmani, E. Sadeghian, and S. Dolatiary, "Comparison between ideal and estimated pv parameters using evolutionary algorithms to save the economic costs," 2018.

[25] Z. Gu and D. T. Rizy, "Neural networks for combined control of capacitor banks and voltage regulators in distribution systems," IEEE transactions on power delivery, vol. 11, pp. 1921-1928, 1996.

[26] B. Rahimikelarijani, A. Abedi, M. Hamidi, and J. Cho, "Simulation modeling of Houston Ship Channel vessel traffic for optimal closure scheduling," Simulation Modelling Practice and Theory, vol. 80, pp. 89-103, 2018.

[27] R. Eini and A. R. Noei, "Identification of Singular Systems under Strong Equivalency," International Journal of Control Science and Engineering, vol. 3, pp. 73-80, 2013.

[28] M. Alizadeh, I. Mahdavi, N. Mahdavi-Amiri, and S. Shiripour, "A capacitated location-allocation problem with stochastic demands using sub-sources: An empirical study," Applied Soft Computing, vol. 34, pp. 551-571, 2015

[29] S. Dolatiary, J. Rahmani, and Z. Khalilzad, "Optimum Location of DG Units Considering Operation Conditions."

[30] M. Ketabdar and A. Hamedi, "Intake Angle Optimization in 90-degree Converged Bends in the Presence of Floating Wooden Debris: Experimental Development," Florida Civ. Eng. J, vol. 2, pp. 2227.2016, 2016.

[31] J. R. Santos, A. G. Exposito, and J. M. Ramos, "A reduced-size genetic algorithm for optimal capacitor placement on distribution feeders," in Proceedings of the 12th IEEE Mediterranean Electrotechnical Conference (IEEE Cat. No. 04CH37521), 2004, pp. 963-966.

[32] S. M. RakhtAla and R. Eini, "Nonlinear modeling of a PEM fuel cell system; a practical study with experimental validation," International Journal of Mechatronics, Electrical and Computer Technology, vol. 4, pp. 1272-1296, 2014.

[33] F. Rahmani, F. Razaghian, and A. Kashaninia, "High Power Two-Stage Class-AB/J Power Amplifier with High Gain and Efficiency," 2014.

[34] M. Alizadeh, N. Mahdavi-Amiri, and S. Shiripour, "Modeling and solving a capacitated stochastic location-allocation problem using sub-sources," Soft Computing, vol. 20, pp. 2261-2280, 2016.

[35] M. Taheri Andani, Z. Ramezani, S. Moazami, J. Cao, M. M. Arefi, and H. Zargarzadeh, "Observer-Based 
Sliding Mode Control for Path Tracking of a Spherical Robot," Complexity, vol. 2018, 2018.

[36] A. Hamedi, M. Ketabdar, M. Fesharaki, and A. Mansoori, "Nappe Flow Regime Energy Loss in Stepped Chutes Equipped with Reverse Inclined Steps: Experimental Development," Florida Civil Engineering Journal, vol. 2, pp. 28-37, 2016.

[37] M. T. Andani, S. Shahmiri, H. Pourgharibshahi, K. Yousefpour, and M. H. Imani, "Fuzzy-Based Sliding Mode Control and Sliding Mode Control of a Spherical Robot," in IECON 2018-44th Annual Conference of the IEEE Industrial Electronics Society, 2018, pp. 2534-2539.

[38] A. Hamedi and M. Ketabdar, "Energy Loss Estimation and Flow Simulation in the skimming flow Regime of Stepped Spillways with Inclined Steps and End Sill: A Numerical Model," International Journal of Science and Engineering Applications, vol. 5, pp. 399-407, 2016.

[39] A. Rouholamini, H. Pourgharibshahi, R. Fadaeinedjad, and G. Moschopoulos, "Optimal tilt angle determination of photovoltaic panels and comparing of their mathematical model predictions to experimental data in Kerman," in Electrical and Computer Engineering (CCECE), 2013 26th Annual IEEE Canadian Conference on, 2013, pp. 1-4.

[40] Yousefpour, Kamran, et al. "Using a Z-Source Inverter as Rotor Side Converter in Doubly-Fed Induction Generator Wind Energy Conversion System." 2019 IEEE Texas Power and Energy Conference (TPEC). IEEE, 2019. 